\title{
New aryloxybenzylidene ruthenium chelates - synthesis, reactivity and catalytic performance in ROMP
}

\author{
Patrycja Żak, Szymon Rogalski, Mariusz Majchrzak, Maciej Kubicki \\ and Cezary Pietraszuk*
}

\author{
Full Research Paper \\ Address: \\ Adam Mickiewicz University in Poznań, Faculty of Chemistry, \\ Umultowska 89b, 61-614 Poznań, Poland \\ Email: \\ Cezary Pietraszuk* - pietrasz@amu.edu.pl \\ * Corresponding author \\ Keywords: \\ chemoactivation; latent catalysts; metathesis; ROMP; ruthenium
}

\author{
Beilstein J. Org. Chem. 2015, 11, 1910-1916. \\ doi:10.3762/bjoc.11.206 \\ Received: 21 July 2015 \\ Accepted: 21 September 2015 \\ Published: 14 October 2015 \\ This article is part of the Thematic Series "Progress in metathesis \\ chemistry II". \\ Guest Editor: K. Grela
}

(c) 2015 Żak et al; licensee Beilstein-Institut.

License and terms: see end of document.

\begin{abstract}
New phenoxybenzylidene ruthenium chelates were synthesised from the second generation Grubbs catalysts bearing a triphenylphosphine ligand (or its para-substituted analogues) by metathesis exchange with substituted 2-vinylphenols. The complexes behave like a latent catalyst and are characterized by an improved catalytic behaviour as compared to that of the known analogues, i.e., they exhibit high catalytic inactivity in their dormant forms and a profound increase in activity after activation with $\mathrm{HCl}$. The strong electronic influence of substituents in the chelating ligand on the catalytic activity was demonstrated. The catalytic properties were tested in ROMP of cyclooctadien (COD) and a single selected norbornene derivative.
\end{abstract}

\section{Introduction}

Olefin metathesis is nowadays one of the most important methods for the formation of carbon-carbon bonds in organic and polymer chemistry [1,2]. The availability of well-defined ruthenium-based catalysts, showing a number of desirable features such as tolerance of functional groups, moisture and air, has significantly expanded the scope and application of this process regardless of dynamic advancement in the development of ruthenium-based metathesis catalysts. Continuous efforts have been aimed at the search for new catalysts characterized by improved stability and catalytic performance. One of the current challenges is the development of catalysts allowing control of initiation for some metathesis polymerisation processes. For such applications a variety of latent catalysts have been reported which permit control of initiation and efficient propagation of the reaction [3-5].

Among numerous examples of latent catalysts, the complexes representing the structural motif illustrated in Figure 1 have 
been relative poorly investigated. Known examples include benzylidenecarboxylate (Figure 2a) [6] and nitronate complexes (Figure 2b) [7] as well as amidobenzylidene ruthenium chelates (Figure 2c-e) that we have disclosed in cooperation with the Grela group [8].

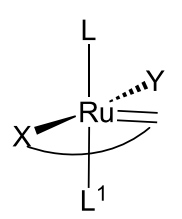

$\mathrm{L}, \mathrm{L}^{1}=\mathrm{PCy}_{3}, \mathrm{NHC}$

$\mathrm{X}, \mathrm{Y}=$ anionic ligands

Figure 1: Coordination motif of latent catalyst of olefin metathesis in which alkylidene ligand is bound to the heteroatom $\mathrm{X}$, acting as an anionic ligand.

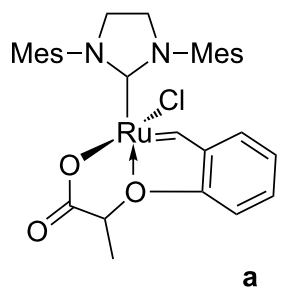

a

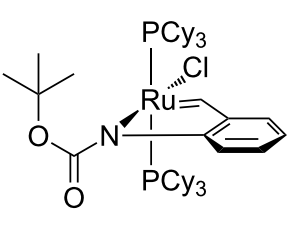

C

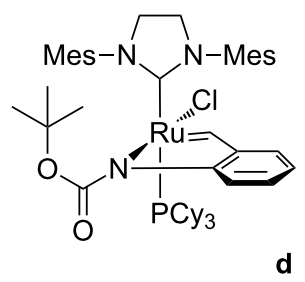

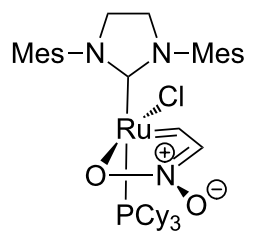

b

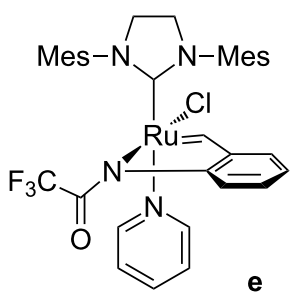

Figure 2: Known latent catalysts of olefin metathesis in which alkylidene ligands are bound to a heteroatom, acting as an anionic ligand.

Recently we have reported a study on aryloxybenzylidene ruthenium chelates (1a-d Figure 3) [9]. Similar complexes have also been independently studied by Skowerski and Grela [10].

Phenoxybenzylidene complexes have been demonstrated to behave like latent catalysts in common testing reactions involving ring opening metathesis polymerisation (ROMP)

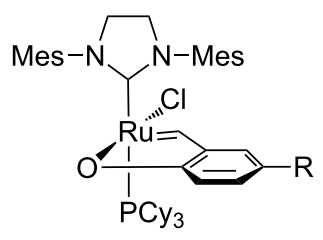

$R=H(1 a), M e(1 b), \mathrm{NO}_{2}(1 c), C l(1 d)$

Figure 3: Selected, known aryloxybenzylidene chelates $[9,10]$.

of COD, norbornene derivative and dicyclopentadiene as well as cross metathesis (CM) of allylbenzene with Z-1,4(diacetoxy)but-2-ene $[9,10]$. Although catalysts 1a-d are characterized by a number of advantages, they are not free from some weaknesses. They showed in some reactions a non-negligible catalytic activity in the absence of activators $[9,10]$ and an instability of the activated forms. Herein, searching for improved latent catalysts that are less reactive in dormant form and highly active in the presence of an chemical activator, we report the synthesis and catalytic performance of new phenoxybenzylidene ruthenium chelates modified by introduction of electron donating and electron withdrawing substituents at the benzylidene ligand in para position to the coordinating oxygen and bearing instead of a strong sigma-donor ligand - tricyclohexylphosphine a weaker sigma-donor - a triphenylphosphine ligand or its derivatives. The catalytic performance of the synthesized complexes were tested in ROMP of COD and a single selected norbornene derivative.

\section{Results and Discussion Synthesis}

Complexes containing triphenylphosphine ligands and substituted triphenylphosphine ligands were isolated in high yields (95-98\%) according to the methodology described by Grubbs (Scheme 1) [11]. However, in our hands to get complete transformation 5 equiv of phosphine had to be used.

In a next step the complexes (4-6) were subjected to metathesis exchange reaction with 2-(prop-1-enyl)phenol (Scheme 2). The reaction was performed in the presence of an equimolar amount of the corresponding phosphine in order to bind the $\mathrm{HCl}$ liberated during the reaction, which resulted in a significant increase in the reaction yield. Complexes $\mathbf{8 - 1 0}$ were easily isolated by precipitation with methanol or hexane from concentrated solution in methylene chloride (isolated yields $=86-90 \%$ ). ${ }^{1} \mathrm{H}$ NMR spectra confirmed the formation of new alkylidene complexes.

Complexes 13 and 14 were prepared by using a similar methodology. Complex 4 was subjected to a metathesis exchange with a slight excess of the appropriate 2-vinylphenol in the presence 

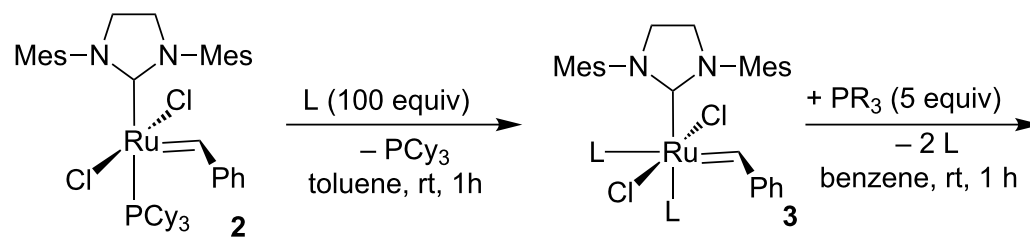

$L=3$-bromopyridine<smiles>CN1CCN(C)C1[Ge](Cl)(Cl)/C=C/P</smiles>

$\mathrm{PR}_{3}=\mathrm{P}\left(\mathrm{C}_{6} \mathrm{H}_{5}\right)_{3}(4)$, $\mathrm{P}\left(\mathrm{C}_{6} \mathrm{H}_{4} \mathrm{CF}_{3}-4\right)_{3}(5)$, $\mathrm{P}\left(\mathrm{C}_{6} \mathrm{H}_{4} \mathrm{Me}-4\right)_{3}(6)$<smiles>CC=Cc1ccccc1O</smiles>

7 (1.1 equiv) synth. of 8: $\mathrm{CH}_{2} \mathrm{Cl}_{2}, 40^{\circ} \mathrm{C}, 24 \mathrm{~h}$ synth. of 9 and 10: $\mathrm{C}_{6} \mathrm{H}_{6}, 60^{\circ} \mathrm{C}, 3 \mathrm{~h}$

Scheme 2: Synthesis of catalysts 8-10.

of triphenylphosphine (Scheme 3). Complexes were obtained with isolated yields of $90 \%$ (complex 13) and $92 \%$ (complex 14).

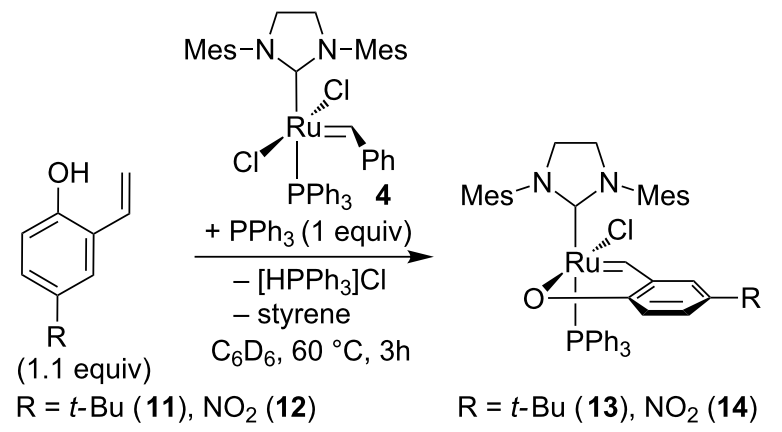

Scheme 3: Synthesis of catalysts 13 and 14.

\section{Catalytic activity}

The obtained complexes were tested in the ring opening metathesis polymerisation (ROMP) of cyclooctadiene. First, the impact of a phosphine ligand on the catalytic activity was investigated. Preliminary tests performed showed, as expected, that in the absence of the activator complexes $\mathbf{1 a}$ and $\mathbf{8 - 1 0}$ were completely inactive $\left(\mathrm{CH}_{2} \mathrm{Cl}_{2}, 40{ }^{\circ} \mathrm{C}, 0.5 \mathrm{M}, 0.1 \mathrm{~mol} \%\right.$ of catalyst). Under the same conditions, in the presence of 2 equivalents of $\mathrm{HCl}$ (used in the form of $2.0 \mathrm{M}$ solution in diethyl ether) as an activating agent, complex 1a was capable for providing a complete conversion after a few minutes of the reaction. Preliminary tests to optimize the concentration of the catalyst showed that complex $\mathbf{1 a}$ in the presence of an activator retained high catalytic activity in the test reaction already at a concentration of $0.005 \mathrm{~mol} \%$ (relative to the monomer). The reaction profiles for the catalysts $\mathbf{1 a}$ and $\mathbf{8 - 1 0}$, both in the dormant form and in the presence of an activator are shown in Figure 4. The results confirm the total lack of activity of complexes in their dormant forms and show a dramatic increase in catalytic activity in the presence of 2 equiv of $\mathrm{HCl}$ as an activator. The chart illustrates an insignificant effect of the properties of the phosphine ligand on the catalytic activity of the complexes. The order of increasing activities of the activated species, i.e., $8\left(\mathrm{PPh}_{3}\right)<\mathbf{1 0} \mathrm{P}\left(\mathrm{C}_{6} \mathrm{H}_{4} \mathrm{Me}-4\right)_{3}<\mathbf{1 a}\left(\mathrm{PCy}_{3}\right)<\mathbf{9}$ $\mathrm{P}\left(\mathrm{C}_{6} \mathrm{H}_{4} \mathrm{CF}_{3}-4\right)_{3}$ does not correlate with decreasing $\sigma$-donor

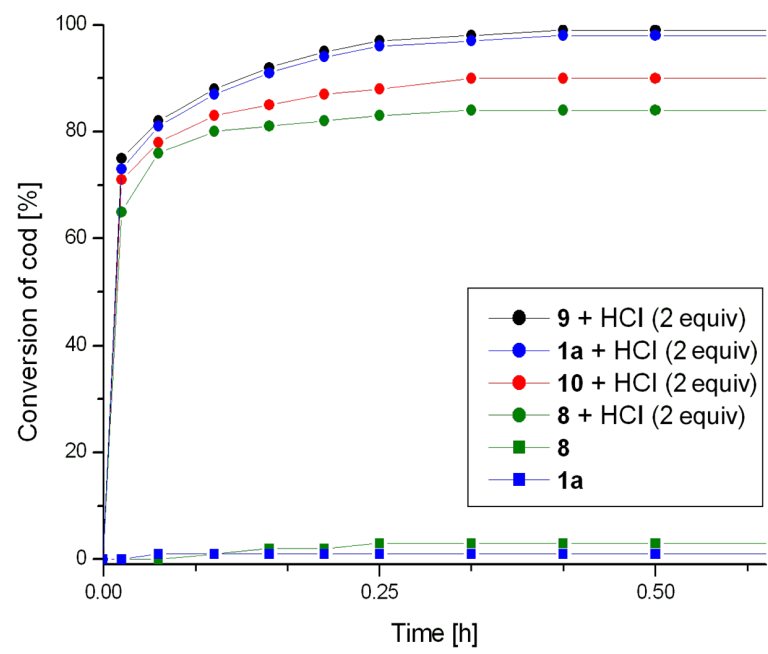

Figure 4: ROMP of COD. Conditions: $\mathrm{CH}_{2} \mathrm{Cl}_{2}, 40{ }^{\circ} \mathrm{C}, 0.5 \mathrm{M}$, $[C O D]:[R u]=20000$; For clarity, only two representative profiles for non-activated catalysts were presented. 
ability of the phosphine ligands (represented by Hammet constant) $[12,13]$. The highest activity was indeed observed for complex 9 containing the weakest $\sigma$-donor and potentially most easily dissociating ligand $\mathrm{P}\left(\mathrm{C}_{6} \mathrm{H}_{4} \mathrm{CF}_{3}-4\right)_{3}$. However, the lowest activity was found for complex 8 containing triphenylphosphine which is characterised by lower $\sigma$-strength than a tris( $p$-tolyl)phosphine present in catalyst $\mathbf{1 0}$ and tricyclohexylphosphine present in the very active catalyst $\mathbf{1 a}$. The increase in activity could be correlated to some extent with growing basicity of the phosphine ligand. More basic phosphine more readily reacted with the activator $(\mathrm{HCl})$ leading to a faster increase in the concentration of the phosphine-free form of the catalyst (Figure 4).

The influence of electronic properties of substituents placed in the aromatic ring of the chelating ligand, in para position to the oxygen covalently bound to the ruthenium atom, was examined by comparing the activity of complexes 8,13 and 14 . Complexes 13 and 14, when used without any activating additives, showed no catalytic activity under the reaction conditions. However, in the presence of two equivalents of $\mathrm{HCl}$, the effect of the electronic properties of the above substituents was significant. Comparison of the activities of catalysts 8,13 and 14 in their dormant forms and in the presence of an activator is shown in Figure 5. The highest activity was observed for catalyst 13 containing an electron donating tert-butyl group at the aromatic ring. In the presence of this catalyst, the addition of the activator resulted in a dramatic increase in catalytic activity, so that complete conversion was observed after a few minutes of the reaction course. On the other hand, the lowest activity was observed for complex $\mathbf{1 4}$ containing a strongly electron

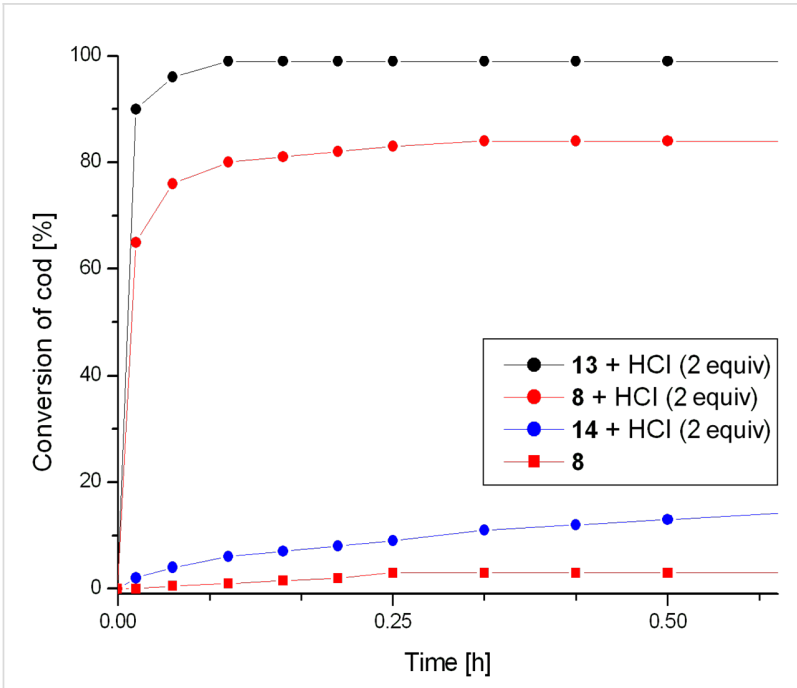

Figure 5: ROMP of cod. Conditions: $\mathrm{CH}_{2} \mathrm{Cl}_{2}, 40{ }^{\circ} \mathrm{C}, 0.5 \mathrm{M}$, [cod]: $[\mathrm{Ru}]=$ 20000; For clarity only representative profile for non-activated catalyst is presented. withdrawing nitro group. In the presence of this catalyst, after $1 \mathrm{~h}$ of the reaction only about $17 \%$ conversion took place. A similar impact of substituents was observed for complexes 1a-c [9]. A reasonable explanation of the activating influence of electron donating groups is an increase in electron density on the chelating oxygen atom generated by a positive inductive effect, which facilitates the protonolysis of the $\mathrm{Ru}-\mathrm{O}$ bond. The strongly electron withdrawing nitro group present in complex 14 caused reduction of the electron density on the oxygen atom and consequently its lower susceptibility to protonolysis which has been earlier proved to be necessary for the catalyst activation [9].

The catalytic performance of phenoxybenzylidene ruthenium chelates 1a, 8, 13 and 14 was also checked in ROMP of a single selected norbornene derivative $\mathbf{1 5}$ (Scheme 4). The reaction progress was monitored by ${ }^{1} \mathrm{H}$ NMR spectroscopy.

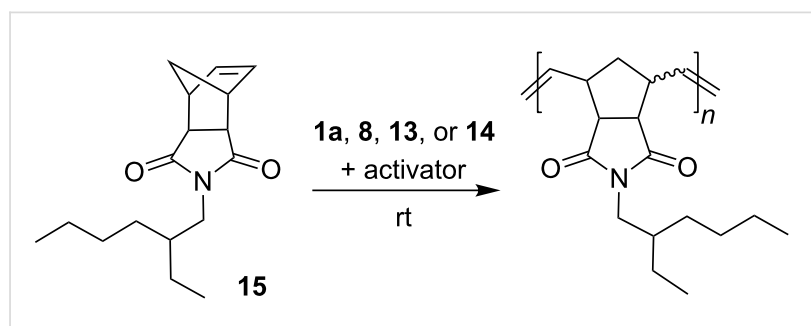

Scheme 4: ROMP of monomer 15.

Inactivated catalyst $\mathbf{1 a}$ does not exhibit catalytic activity in ROMP of 15 performed at room temperature $\left(23^{\circ} \mathrm{C}\right)$. When $\mathrm{HCl}$ is added, the activity of complex $\mathbf{1 a}$ increases, but after $2 \mathrm{~h}$ of the reaction course only about $30 \%$ monomer conversion was observed. At $40{ }^{\circ} \mathrm{C}$, complex $\mathbf{1 a}$ used without an activator remained inactive, but the addition of $\mathrm{HCl}$ led to complete monomer conversion within $2 \mathrm{~h}$ (Figure 6). In a separate experiment performed at room temperature the activated complex $1 \mathbf{a}$ gave $90 \%$ monomer conversion within $2 \mathrm{~h}$, by using a monomer to catalyst ratio as high as 2000 .

Preliminary studies of ROMP of monomer $\mathbf{1 5}$ in the presence of activated complexes $\mathbf{8}, \mathbf{1 3}$ and $\mathbf{1 4}$ revealed their significantly higher catalytic activity than that of activated complex 1a; that is why a further study of ROMP was performed at room temperature. In the absence of an activator, the reaction over all these complexes gave only trace monomer conversion (Figure 7). After the activation with 2 equiv $\mathrm{HCl}$, complete monomer conversion was observed to occur within $30 \mathrm{~min}$ in the presence of catalyst 8 and within 20 min for catalyst 13. Complex 14 exhibits significantly lower activity. After $1 \mathrm{~h}$ only $22 \%$ conversion was noted and complete monomer consumption required $24 \mathrm{~h}$ of the reaction course. 


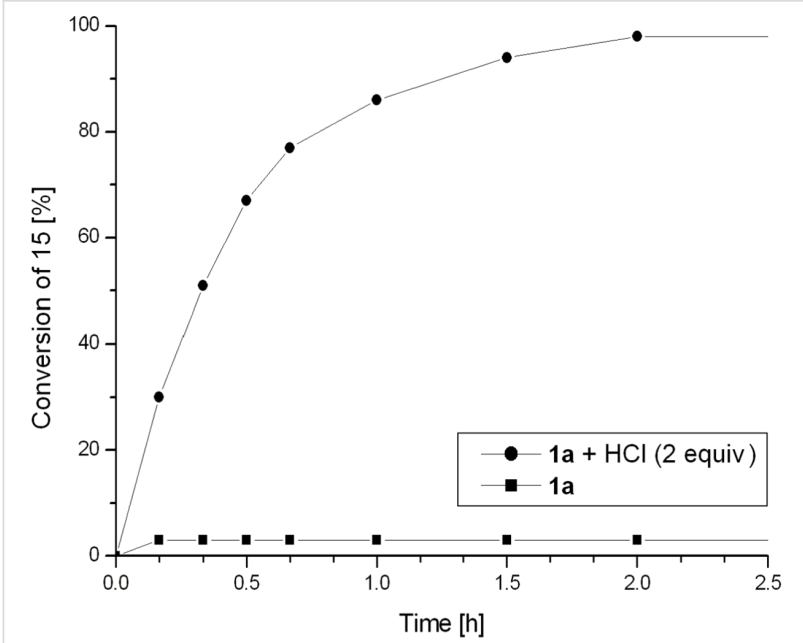

Figure 6: ROMP of monomer 15. Conditions: $\mathrm{CDCl}_{3}, 40^{\circ} \mathrm{C}, 0.08 \mathrm{M}$, $[15]:[R u]=200$.

\section{Activation process study}

Our earlier studies of the activation of complex 1a with an ethereal solution of $\mathrm{HCl}$ have proved that the chelate ring opening by cleavage of the $\mathrm{Ru}-\mathrm{O}$ bond is necessary for getting the catalytically active form of this complex [9]. On the other hand, the studies of the effect of $\mathrm{CuCl}$, acting as a phosphine scavenger, on the activity of complex 1a in ROMP of COD revealed a small activating effect [9]. An analogous study performed for ROMP of COD catalysed with complex $\mathbf{8}$ did not confirm the activating impact of $\mathrm{CuCl}$. Complex $\mathbf{8}$ used alone or in the pres-

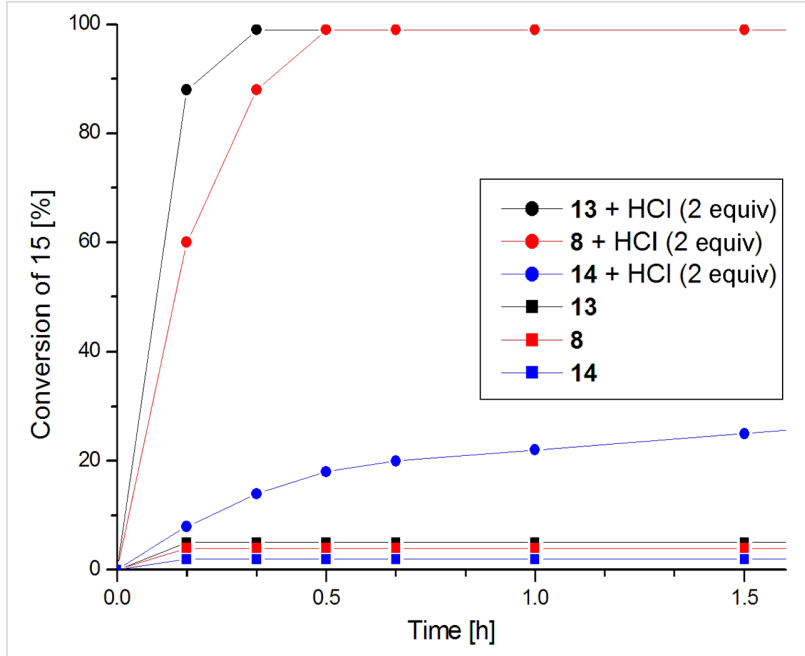

Figure 7: ROMP of monomer 15. Conditions: $\mathrm{CDCl}_{3}, 23^{\circ} \mathrm{C}, 0.08 \mathrm{M}$, $[15]:[R u]=200$

ence of 2-5 equiv of $\mathrm{CuCl}$ was totally inactive. In order to elucidate the possible transformations taking place in the system phenoxybenzylidene chelate/ $\mathrm{CuCl}$, a benzene solution of complex 8 was heated with 1 equiv of $\mathrm{CuCl}$ at $60^{\circ} \mathrm{C}$. After $24 \mathrm{~h}$ of the reaction course, the formation of a green precipitate was observed. X-ray diffraction analysis of single crystals obtained by slow evaporation of the post-reaction mixture revealed the formation of dimeric complex 16, in which the phenoxybenzylidene ring was conserved (Figure 8), which points to the reaction proceeding according to Scheme 5 .

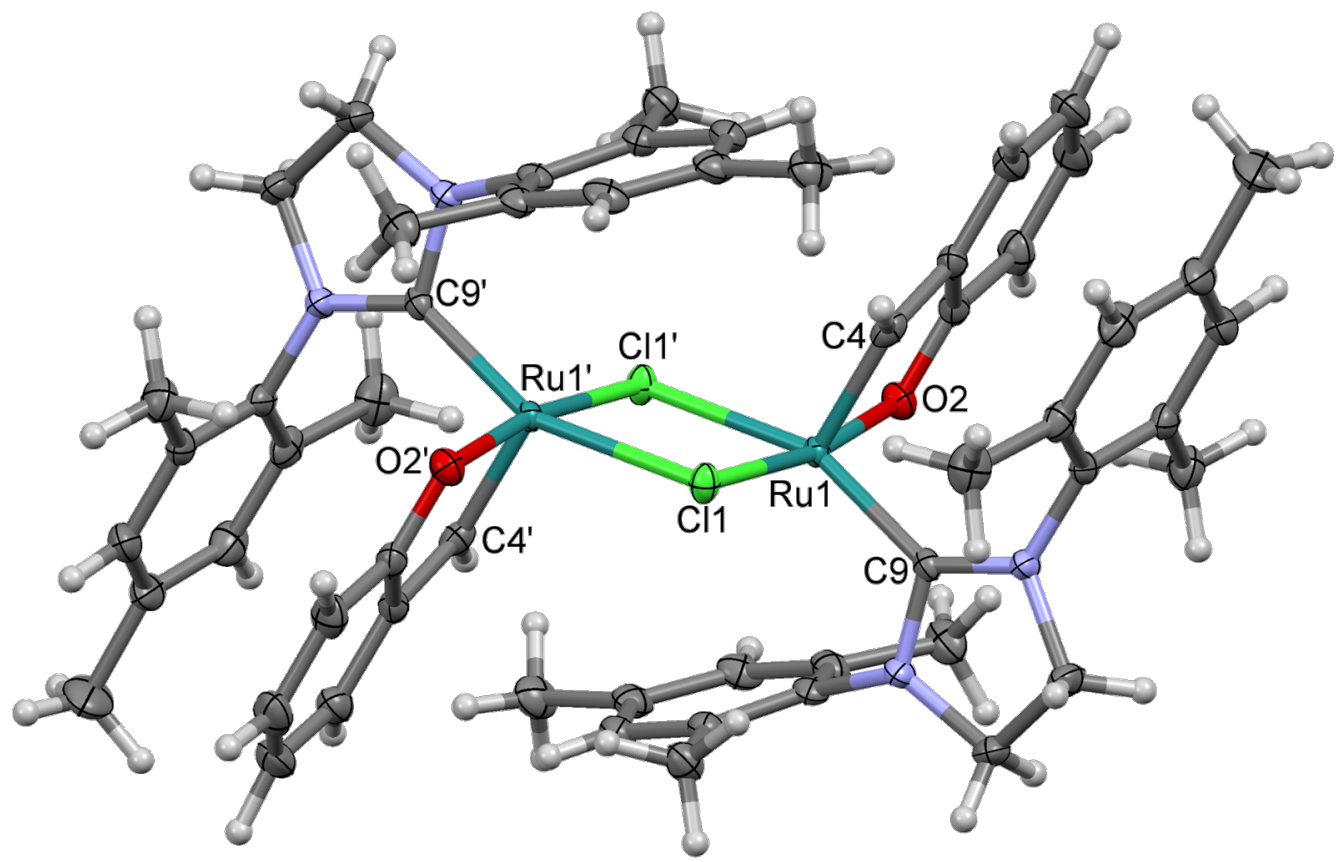

Figure 8: A perspective view of complex 16, the ellipsoids are drawn at the $50 \%$ probability level. Hydrogen atoms are drawn as spheres of arbitrary radii. 


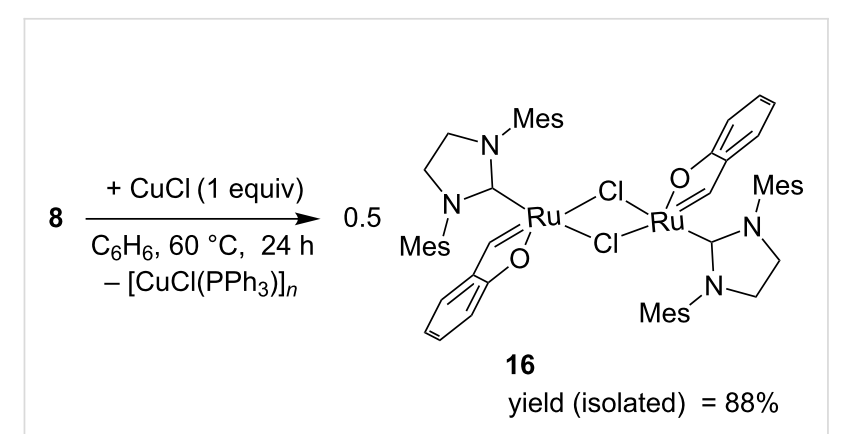

Scheme 5: Formation of phosphine free dimeric complex in the presence of $\mathrm{CuCl}$.

Similar transformation was observed with the use of complex 1a as a starting compound [9]. The reaction was particularly effective in benzene because of poor solubility of the dimer in this solvent.

As it is common for ruthenium-alkylidene complexes active in metathesis, the coordination of the Ru atom might be described as a distorted tetragonal pyramid, with the carbon atom doublebonded to $\mathrm{Ru}(\mathrm{C} 4)$ in the apex of the pyramid. The distortions in the dimer are more pronounced than in the similar mononuclear complex 1a (see supplemetara data of [9]), but still four base atoms; two chlorines, carbon $\mathrm{C} 9$ and oxygen $\mathrm{O} 2$ are planar within ca. $0.22 \AA, \mathrm{Ru}$ lies also quite well within this plane $(0.17 \AA)$, and only the $\mathrm{C} 4$ atom is by $1.99 \AA$ distant from the plane. The $\mathrm{Ru}-\mathrm{C}$ line makes an angle of ca. $8.6^{\circ}$ with the normal to the mean basal plane. The double-bond Ru1-C4 (1.841(3) $\AA$ ) is significantly shorter than the formally single $\mathrm{Ru}-\mathrm{C} 9$ bond of 1.974(2) A. Probably due to the steric requirements, $\mathrm{Ru}-\mathrm{Cl}$ distances in the dimer are longer than in mononuclear complex 1a (2.4145(5) and 2.42775(5) $\AA$, as compared to $2.3827(4))$, while the other bonds are slightly $(\mathrm{Ru}=\mathrm{C}: 1.841(3)$ vs $1.8499(18) \AA, \mathrm{Ru}-\mathrm{O}: 2.0720(16)$ vs $2.0936(12)$ or significantly (Ru-O: 1.974(2) vs 2.0720(16)) shorter. Complex 16 showed no catalytic activity in the ROMP of COD under the conditions used $\left(\mathrm{CH}_{2} \mathrm{Cl}_{2}, 40{ }^{\circ} \mathrm{C}, 0.5 \mathrm{M}, 0.005-0.1 \mathrm{~mol} \%\right.$ relative to the monomer). The observed catalytic inactivity was found not to be a consequence of conservation of chelating phenoxybenzylidene ring in the dimer structure but results from the fast decomposition of complex $\mathbf{1 6}$ in solution, leading to the loss of alkylidene moiety. However, when a suspension of dimer 16 in $\mathrm{CH}_{2} \mathrm{Cl}_{2}$ was treated with an equimolar amount of triphenylphosphine formation of complex $\mathbf{8}$ with an almost quantitative yield was observed. A similar reaction was observed when strongly nucleophilic $\mathrm{PCy}_{3}$ was used (Scheme 6). The reaction can be successfully used as an alternative method for the synthesis of a variety of phenoxybenzylidene chelates (see Experimental).

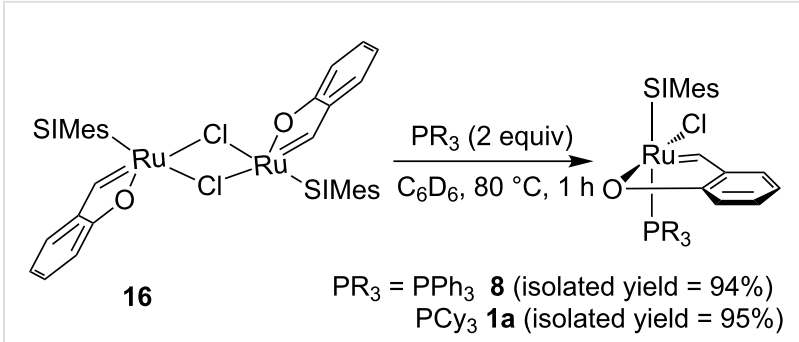

Scheme 6: Synthesis of complexes 1a and 8 starting from dimer 16

According to the earlier described activation mechanism [9], the reaction of phenoxybenzylidene chelates with 1 equiv of $\mathrm{HCl}$ leads to protonation of the oxygen atom in the $\mathrm{Ru}-\mathrm{O}$ bond, which results in the breaking of the bond and introduction of a chloride anion into the coordination sphere of ruthenium. Exposition of complex 8 to one equivalent of $\mathrm{HCl}$ brought a change in the solution colour from green to light-green. The fine-crystalline light-green precipitate was isolated from the post-reaction mixture by precipitation with hexane with $95 \%$ isolated yield. The precipitate was stable as solid and sufficiently stable in a $\mathrm{CD}_{2} \mathrm{Cl}_{2}$ solution to permit recording of its ${ }^{1} \mathrm{H}$ and ${ }^{31} \mathrm{P}$ NMR spectra. On the basis of the data obtained the reaction was proposed to proceed according to Scheme 7. However, it was impossible to identify in the ${ }^{1} \mathrm{H}$ NMR spectrum the signal that could be assigned to the hydroxy group. It is most probably a consequence of high lability of this proton and its suitability for exchange with deuterium coming from the NMR solvent $\left(\mathrm{CD}_{2} \mathrm{Cl}_{2}\right)$ as it was observed for activated complex 1a [9].

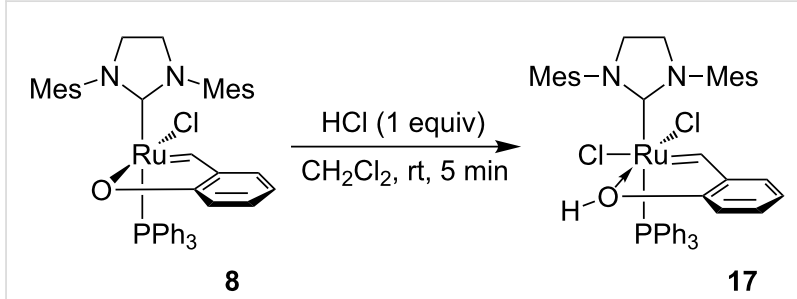

Scheme 7: Activation of complex 8 with one equivalent of $\mathrm{HCl}$.

Complex 17 was proved to exhibit high catalytic activity in ROMP of the monomers tested. In ROMP of COD $\left(\mathrm{CH}_{2} \mathrm{Cl}_{2}\right.$, $\left.40{ }^{\circ} \mathrm{C}, 0.5 \mathrm{M},[\mathrm{COD}]:[\mathrm{Ru}]=20000\right)$ it permits obtaining complete conversion after $10 \mathrm{~min}$ of the reaction course. Performed tests of ROMP of monomer 15 showed complete conversion within $15 \mathrm{~min}\left(\mathrm{CDCl}_{3}, 23{ }^{\circ} \mathrm{C}, 0.08 \mathrm{M},[15]:[\mathrm{Ru}]=200\right)$ and within $1 \mathrm{~h}$ when using monomer to catalyst ratio equal to 2000 .

\section{Conclusion}

Ruthenium-benzylidene complexes bearing a triphenylphosphine ligand or its para-substituted analogues undergo 
metathetic exchange with 2-(prop-1-enyl)phenol or substituted 2-vinylphenols to form phenoxybenzylidene ruthenium chelates. These complexes in the phenoxide form exhibit nearly no activity in ROMP of COD and an exemplary norbornene derivative. However, they can be easily activated by addition of an ethereal solution of $\mathrm{HCl}$. The catalytic activity in their active forms was found to be related to the basicity and nucleophilicity of the phosphine ligands. A strong electronic influence of the substituent in the ring of the phenoxybenzylidene ligand, in para position towards the oxygen atom, on the catalytic activity of the active form of the complexes was found. The presence of an electron-donating tert-butyl substituent gave a significant increase in the complex activity, while in the presence of a strongly electron-accepting nitro group the strong opposite effect was observed. When compared to the earlier described analogous complexes, the new phenoxybenzylidene chelates exhibit profound catalytic inactivity in their dormant forms and an improved catalytic activity (after activation) in ROMP of tested monomers.

\section{Experimental}

See Supporting Information File 1 for full experimental data including general methods and chemicals, syntheses and characterization of complexes, procedures of catalytic tests and X-ray analysis.

\section{Supporting Information}

\section{Supporting Information File 1}

General methods and chemicals, syntheses and characterization of complexes 8-10, 13, 14, 16 and 17, procedures of catalytic tests and X-ray analysis. [http://www.beilstein-journals.org/bjoc/content/ supplementary/1860-5397-11-206-S1.pdf]

\section{Acknowledgements}

Financial support from the National Science Centre (Poland), (project No. UMO-2011/03/B/ST5/01047) is gratefully acknowledged.

\section{References}

1. Grela, K., Ed. Olefin Metathesis. Theory and Practice; Wiley: Hoboken, 2014. doi:10.1002/9781118711613

2. Grubbs, R. H.; Wenzel, A. G.; O'Leary, D. J.; Khosravi, E., Eds. Handbook of Metathesis; Wiley-VCH: Weinheim, 2015. doi:10.1002/9783527674107

3. Vidavsky, Y.; Anaby, A.; Lemcoff, N. G. Dalton Trans. 2012, 41, 32-43. doi:10.1039/C1DT11404B

4. Szadkowska, A.; Grela, K. Curr. Org. Chem. 2008, 12, 1631-1647. doi:10.2174/138527208786786264
5. Monsaert, S.; Lozano Vila, A.; Drozdzak, R.; Van Der Voort, P.; Verpoort, F. Chem. Soc. Rev. 2009, 38, 3360-3372. doi:10.1039/b902345n

6. Gawin, R.; Makal, A.; Woźniak, K.; Mauduit, M.; Grela, K. Angew. Chem., Int. Ed. 2007, 46, 7206-7209. doi:10.1002/anie.200701302 Angew. Chem. 2007, 119, 7344-7347. doi:10.1002/ange.200701302

7. Wdowik, T.; Samojłowicz, C.; Jawiczuk, M.; Malińska, M.; Woźniak, K.; Grela, K. Chem. Commun. 2013, 49, 674-676. doi:10.1039/C2CC37385H

8. Pietraszuk, C.; Rogalski, S.; Powała, B.; Miętkiewski, M.; Kubicki, M.; Spólnik, G.; Danikiewicz, W.; Woźniak, K.; Pazio, A.; Szadkowska, A.; Kozłowska, A.; Grela, K. Chem. - Eur. J. 2012, 18, 6465-6469. doi:10.1002/chem.201103973

9. Żak, P.; Rogalski, S.; Przybylski, P.; Kubicki, M.; Pietraszuk, C. Eur. J. Inorg. Chem. 2014, 1131-1136. doi:10.1002/ejic.201301208

10. Kozłowska, A.; Dranka, M.; Zachara, J.; Pump, E.; Slugovc, C.; Skowerski, K.; Grela, K. Chem. - Eur. J. 2014, 20, 14120-14125. doi:10.1002/chem.201403580

11. Sanford, M. S.; Love, J. A.; Grubbs, R. H. Organometallics 2001, 20 , 5314-5318. doi:10.1021/om010599r

12. Love, J. A.; Sanford, M. S.; Day, M. W.; Grubbs, R. H. J. Am. Chem. Soc. 2003, 125, 10103-10109. doi:10.1021/ja027472t

13. Ewing, D. F. In Correlation Analysis in Chemistry; Chapman, N. B.; Shorter, J., Eds.; Plenum: New York, 1978; pp 357-396. doi:10.1007/978-1-4615-8831-3_8

\section{License and Terms}

This is an Open Access article under the terms of the Creative Commons Attribution License (http://creativecommons.org/licenses/by/2.0), which permits unrestricted use, distribution, and reproduction in any medium, provided the original work is properly cited.

The license is subject to the Beilstein Journal of Organic Chemistry terms and conditions:

(http://www.beilstein-journals.org/bjoc)

The definitive version of this article is the electronic one which can be found at:

doi:10.3762/bjoc. 11.206 